\title{
Study on Construction of Dynamic Assessment System for College Online English Writing
}

\author{
Yu Yang, Dongyuan Deng \\ Kunming University of Science and Technology, Kunming, China
}

\begin{abstract}
Summative assessment is widely used in college English writing in China, which emphasizes the product greatly and ignores the writing process. Thus, it cannot improve students' writing proficiency effectively. This paper aims to introduce the application and construction of dynamic assessment system for college online English writing in science university. Finally the feedback from students is discussed and they think highly of this assessment system.
\end{abstract}

KEYWORD: dynamic assessment; online college English writing; writing proficiency

\section{INTRODUCTION}

Summative assessment is widely used in college English writing in China, which emphasizes the product greatly and ignores the writing process. Thus, it cannot improve students' writing proficiency effectively. Syllabus for College English Teaching established in 2007 emphasized that allrounded, objective and scientific assessment system was of greater importance to attain goals for college English teaching, especially for formative assessment. Thus, it is quite necessary for universities and colleges to carry out different forms of assessment to keep track of its English teaching and improve the English proficiency for their students. The focus on process and stage is emphasized in formative assessment, which is also dynamic. For this reason, it is a must to introduce dynamic assessment in college English writing to improve the writing proficiency of students and the teaching efficiency.

On the other hand, with the development of modern informational technology, many universities are aiming to move forward the mode of college English teaching based on Internet, in the hope of offering technological support and convenience for information search. Therefore, it is becoming a tendency to introduce dynamic assessment to online college English teaching.

Traditional summative assessment attempts to summarize students' learning at some point in time, say the end of a course, but can not provide the immediate, contextualized feedback useful for helping teacher and students during the learning process (Garb, 2008), so the dynamic and holistic feature of process writing approach cannot be fully exploited. Laura (1995), when talking about the problems in writing instruction, stressed the importance of assessment method in process writing instruction, "Instruction and assessment must be of the same philosophy. It is unfair to assess process writing with traditional assessment. Furthermore, assessment and evaluation must be viewed as integral, planned parts of the writing curriculum; students need to be actively involved with the teacher in understanding, assessing, and evaluating the writing process."

Dynamic assessment was first posed by Luria in 1961, which was based on the theory of Social Culture by Vygotsky. $\operatorname{Lidz}(2003)$ pointed out that dynamic assessment is conducted based on interactions between assessors and students, and it is intended to explore and discover the potential of students especially under the help of experienced assessors. That is to say, dynamic assessment system is established to develop the potential in the way of interaction. Numerous study and research have been done on the relationship between dynamic assessment and second language teaching (Ableeva, 2008; Anton, 2003; Poehner \& Lantoif, 2005). Poehner found that dynamic assessment can analyze English proficiency of language learners effectively and predict the future development of them.

In China, it is still a new field for dynamic assessment. By far, Han Baocheng(2009) presented a general survey and review on application of dynamic assessment in foreign language teaching. Zhang Yanhong(2008), Lan Xiaoxiao and Liu Yan(2010) 
has put it into teaching of English writing. However, it has aroused great interests of scholars and teachers, which will provide a new perspective for second language teaching.

\section{CONSTRUCTION OF DYNAMIC ASSESSMENT SYSTEM FOR COLLEGE ENGLISH WRITING IN SCIENCE UNIVERSITY}

It has been a headache for teachers that it is a waste of efforts but with low effectiveness for college English teaching. Fang Yan found that lacking of effective teaching method especially absence of effective assessment method is the main reason and teachers may not give students satisfactory feedback. This phenomenon is more seen in science universities. Taking our university for example, normal college English writing is accomplished in the pattern of "Teacher assigning---students" handing in----teacher's feedback", in which teachers grade students' compositions by their final and only products from aspects of language, content and organization. This is called summative assessment, and teachers cannot give individual guidance for students because of painstaking teaching. In informal interview, students are not satisfied with this way of grading and they usually focus on the final marks of their compositions, while ignoring the further revision. For another, teachers' awareness about using network platform is still weak and they rarely do research on online teaching and communication.

Therefore, it is a must for us to make use of online resources to conduct the reform of teaching of college English writing and establish dynamic assessment system. The frame is based on process writing.

Focus of EFL writing instruction in China has changed from the end product to the writing process in the past several years (Best, 1995). According to many researchers, process writing instruction suits better than traditional methods in meeting the needs of the modern information society (Deng, 2003; Jia, 1998). Then lots of researchers contribute most of their efforts to perfect EFL writing process instruction, and a great number of practitioners try to apply the steps of writing process - generating ideas, structuring, drafting, revising and editing, into their writing courses in the hope of better enhancing learners' independent writing ability than traditional approach (White \& Arndt, 1991). Though process writing approach has been used widely in classrooms throughout the world, the way to respond to learners' writing, or the way to assess learners' compositions becomes an emergent issue. Nation-wide researches about EFL writing assessment indicate that some practitioners have adopted some modified assessment methods, such as self assessment, peer assessment, and teacher conference, etc., but the limitations are obvious. First, the number of empirical research papers on assessment of process writing is few. According to Yao \& Cheng's (2005) statistic research on the development of English writing in China since 1980s, there are only 3 pieces (Chen, 1994; Yang, 1996; Zuo, 2002) of such kind papers among the 165 referred pieces. Second, the design of assessment lacks proper supporting theory. Yang (1996), for example, made his research merely based on foreign researchers' assessment practice (Zamel, Fathman, Whalley, Hyland, etc.). Third, the research of assessment is confined to either several assessment methods in one step of writing process or one assessment method during the whole process. Yang (1996), for instance, only used teacher assessment to evaluate students' composition from grammar error correction and content comment in the steps of revising draft and editing. Fourth, although the available research findings could show various assessment methods' advantages in promoting English learners' writing ability, there are still some requirements from English learners, involving being puzzled in how to begin writing and what to write, having trouble in using grammar properly in their compositions, being confused of the criteria of good writing, etc. (Cai \& Fang, 2006).

The details are as follows. And we can see from the above table, all the stages of writing are conducted on Internet except for pre-writing stage. In each stage, teachers will participate in guiding and manipulating students to make assessments on their performance.

Table 1. Construction of Dynamic Assessment System

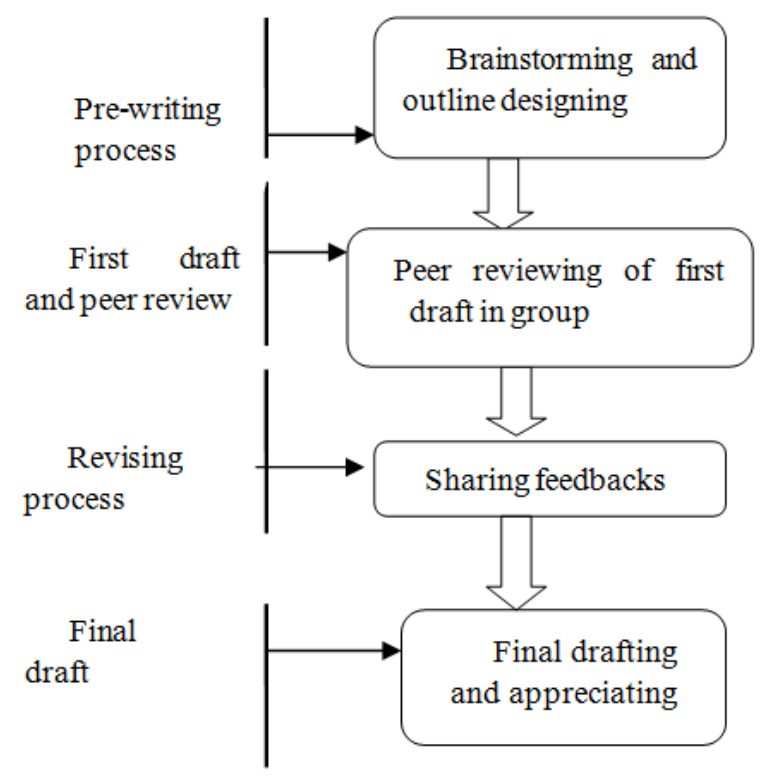

\subsection{Pre-writing}

In this stage, students are required to make thesis statements on assigned topic by involving in prewriting process. Brain storming, free writing and 
loop writing are employed to intensify the topic and narrow down their own topic by making an outline. All the performance in this stage is assessed in class, by which teachers can judge whether the students can start writing or not.

\subsection{First drafting and peer reviewing}

Students are required to write their first drafts based on their prepared outline. Meanwhile, they are divided into several groups with three members, and review others' first draft from aspects of theme, organization and language. After reviewing, teachers will allot the reviewed compositions to different group members to do the second review. To ensure students can make reasonable and appropriate comments, teachers will train them how to assess compositions effectively.

\subsection{Draft revising}

After peer review, teachers will send the reviewed drafts to students on network platform and ask students to make self-revision. At the meanwhile, teacher will provide some references on Internet to help students to do further revision. If necessary, teacher will open online communication forum to answer questions and give them individual help. It is worth mentioning that students will revise their drafts for many times and each revision is done under the teacher's help. Then the final draft is composed.

\subsection{Final drafting}

For the final draft, it will be assessed in two ways: self-assessment and online-voting assessment. For self-assessment, they must check their own draft to make sure there are no spelling mistakes and they have to fill in the self-assessment form to make comments on content, logic and language. Onlinevoting easement refers to the stage of voting for excellence. All compositions will be posted online and are numbered. Students will choose three of them to vote. Finally the votes are counted to rank the first three. Students will be awarded for their excellent works.

After the above-mentioned four-stage assessments, final grades of compositions will be given based on their performance. Performance in pre-writing comprises $20 \%$ and is given by teacher; performance in first drafting and peer reviewing makes up $30 \%$ and is given by the result of peer review; performance in revising stage also accounts for $30 \%$ according to the attitude in revision and its quality; performance in final part is assessed by voting and teacher's final grading, which is $20 \%$ of the total.

\section{APPLICATION OF DYNAMIC ASSESSMENT SYSTEM IN COLLEGE ENGLISH WRITING}

After dynamic assessment system is established, teacher will conduct online teaching of college English writing based on network platform in Kunming University of Science and Technology. The website

is http://eol.kmust.edu.cn/eol/homepage/common/ and free open to all students in our university. Different types of materials can be added to assigned models. The main structure of network platform is composed of more than ten parts including teaching materials, questions and answers (bbs is included), emails, questionnaires, teaching notes, homework and online testing. A lot of materials and reference books on writing are added such as essays appreciation, grammar, writing techniques and vocabulary distinguishing. Students can choose any of them to learn after class.

In pre-writing stage, teacher will start a discussion on assigned topic to arouse students understanding on the topic. In peer reviewing stage, task of writing can be distributed to all students online and emails on detailed assessment will be sent to all students. E-forms are required to fill in to make students know better about self-assessment. After peer review, all compositions with feedback will be sent to corresponding students and they will make further revisions under the teacher's guidance.

To help students to get better knowledge about grammar, students can send their writing to Juku network (http://www.pigai.org) to make self-check. This network can offer suggestions on spellings, collocations, ambiguous vocabulary and sentence patterns.

In final part, e-porfolios based on their performance in each stage will be made and teacher will give feedback to students to help the final revision of the task. And the grades will be made to assess their performance.

\section{FEEDBACK FROM STUDENTS}

This practice is done for one semester and after the final examination, an interview is conducted to the students to get to know the feedback on this practice. Three questions are included: What do you think of the assessment system? Do you understand the details of assessing compositions? Does it have effects on your writing proficiency?

Among 45 students, $92 \%$ of them think highly of this teaching model and hold positive attitude towards this assessment system. It offers a better communicating platform for them to discuss and express the ideas freely. Self-checking on Pigai net is also helpful for them to improve their proficiency in grammar. $85 \%$ of them pointed out they could 
assess the works of own and others appropriately after the training from teacher. $96 \%$ of them think it has positive effect on their study and improve their writing proficiency.

\section{CONCLUSION}

This papers aims to establish the dynamic assessment system of online college English writing based on network platform in Kunming University of Science and Technology. In this system, selfassessment and peer review are of great importance to enhance their interests in writing. Based on practice, this system can facilitate the learning of students, and improve their writing proficiency. However, how to train students to assess the compositions effectively and how teacher can offer online guidance is worth exploring in future study.

\section{ACKNOWLEDGMENT}

The study is supported by the College English Teaching Reform Fund in Yunnan (Yunnan Higher
Education [2013]40), and Yunnan Social Science Project (YB2013072).

\section{REFERENCES}

[1] Ableeva, R. The effects of dynamic assessment on L2 listening comprehension. In Lantolf, J.P. \& M.E. Poehner (eds.). Sociocultural Theory and the Teaching of Second Languages .London: Equinox, 2008.

[2] Lantolf, J. P. \& M. E. Poehner. Dynamic assessment of L2 development: Bringing the past into the future.Journal of Applied Linguistics, 2004, 1: 49-72.

[3] Poehner, M. E. Beyond the test: L2 dynamic assessment and the transcendence of mediated learning .The Modern Language Journal, 2007, 91 (3): 323-340.

[4] Vygotsky, L. S. Mind in Society: The Development of Higher Psychological Processes. Cambridge: Harvard University Press, 1989: 107-109.

[5] Cai, Huiping \& Fang, Yan. Investigation and analysis of teaching writing in English in China. Foreign Languages and Their Teaching, 2006, (.9).

[6] Chen, Hai. Correction of college English writing. Foreign Language World, 1994, (.3).

[7] Deng, Liming. A systematic study of process approach and its implications for the teaching reforms of college English writing. Foreign Language Education, 2003, (6). 